\title{
An Evaluation of Tumor, Patient Characteristics and Survival in Squamous Cell Carcinoma Arising from Different Types of Oral Epithelia
}

\author{
${ }^{1}$ Amitha J Lewis, ${ }^{2}$ Karen Boaz, ${ }^{3}$ Manish Juneja, ${ }^{4}$ Srikant Natarajan, ${ }^{5}$ Aashima Mohindra, ${ }^{6}$ Mohan Baliga
}

\begin{abstract}
Aim: Squamous cell carcinoma is the most common malignancy affecting the oral cavity. In spite of advanced therapeutic interventions, it is still a common cause of morbidity and mortality worldwide. The clinical presentation and prognosis of the carcinomas occurring at different sites in the oral cavity is varied and could be explained by the difference in the type of epithelia from which they originate. Therefore this study aimed to assess the patient and tumor characteristics, clinical presentation and behavior of a sample of oral squamous cell carcinomas (OSCC) to determine the parameters most likely to influence the prognosis based on the origin of the epithelium.
\end{abstract}

Materials and methods: Eighty-nine cases of histologicallyproven oral squamous cell carcinoma with a minimum followup of three years were categorized based on their epithelia of origin. The clinical follow-up data and survival were collected from the patient's records. New malignancy grading by Anneroth et al. was utilized for histopathological grading following which the lymph nodes (in cases of neck dissection) were assessed for evidence of nodal metastasis.

Results: Most of the carcinomas originated from the nonkeratinized epithelium $(42.7 \% n=38)$ followed by the keratinized epithelium. Carcinomas arising from the non-keratinized epithelium had the poorest outcome with a mortality of $27.7 \%$ $(n=10)$ and disease-free survival of $38.8 \%(n=14)$ at the end of 36 months.

Conclusion: The present study though limited in its sample size and follow-up concluded that the nature of epithelium of origin has a bearing on the prognosis of oral squamous cell carcinoma.

Clinical significance: Knowledge of the prognostic significance of the oral squamous cell carcinomas based on the type of epithelia of origin will help the clinicians to plan a more aggressive treatment plan for patients with carcinomas originating from the non-keratinized epithelium.

Keywords: Mortality, Oral cancer, Prognosis, Recurrence, Squamous cell carcinoma, Survival analysis.

\footnotetext{
${ }^{1-5}$ Department of Oral Pathology and Microbiology, Manipal College of Dental Sciences, Manipal Academy of Higher Education, Mangaluru, Karnataka, India

${ }^{6}$ Department of Oral and Maxillofacial Surgery, Manipal College of Dental Sciences, Manipal Academy of Higher Education, Mangaluru, Karnataka, India

Corresponding Author: Karen Boaz, Department of Oral Pathology and Microbiology, Manipal College of Dental Sciences, Manipal Academy of Higher Education, Mangaluru, Karnataka, India, Phone: +919343560905, e-mail: karen.boaz@ manipal.edu
}

How to cite this article: Lewis AJ, Boaz K, Juneja M, Natarajan S, Mohindra A, Baliga M. An Evaluation of Tumor, Patient Characteristics and Survival in Squamous Cell Carcinoma Arising from Different Types of Oral Epithelia. World J Dent 2018;9(6):468-475.

Source of support: Nil

Conflict of interest: None

\section{INTRODUCTION}

Oral cancer is a significant cause of morbidity and mortality worldwide with an incidence rate that varies widely by geographic location. Even within a geographic area, the incidence varies among groups categorized by age, sex or race. Incidence rates also change over time. ${ }^{1}$ Oral cancer is the eighth most common cancer globally with males having a higher prevalence, and in South Central Asia it is the third most common type of cancer. In India, the incidence rate is 12.6 per 100000 population, most of which are fatal. ${ }^{2}$

The overall 5-year survival rate of patients with oral squamous cell carcinoma is less than $50 \% .^{2,3}$ The etiology for OSCC is multifactorial, and it exhibits different clinical and biological behavior. The data regarding the varied clinical presentation and behavior of OSCCs may at least in part be explained by the type of epithelia they have originated from. There are three different types of epithelia in the oral cavity: keratinized masticatory mucosa, non-keratinized lining mucosa and specialized mucosa of the tongue. Each of these epithelia has significant differences in their development, structure, and function with variation in turn over time, protein content, and composition of cellular adhesion proteins as well as molecular characteristics such as cytokeratin profile. The nature of the epithelium may play a significant factor that influences the prognosis of oral cancer. ${ }^{4,5}$

The present study aimed to assess the patient and tumor characteristics, clinical presentation and behavior of a sample of oral squamous cell carcinomas to determine the parameters most likely to influence the prognosis based on the type of epithelia of origin.

\section{MATERIALS AND METHODS}

This retrospective study included 89 histologically-proven cases of oral squamous cell carcinoma. Cases treated 
by surgery and/or radiation and with a minimum followup of 3 years (36 months) were included in the study. Cases with no follow-up were excluded from the study. The proposal for the study received clearance from the Institutional Ethics Committee. The tumors (OSCC) were categorized according to the type of oral epithelium they originated from as:

- Keratinized (masticatory) epithelium: OSCC of the alveolus, palatal region, and lip

- Non-keratinized (lining) epithelium: OSCC of buccal mucosa, the floor of mouth, soft palate and ventral surface of the tongue

- Specialized epithelium: OSCC of the dorsal tongue

- Tongue epithelium (other than dorsum of the tongue): OSCC of the lateral border of the tongue

The clinical data regarding age, gender, site, clinical presentation of a tumor and TNM stage (AJCC 1997) were recorded from the patient's files. Presence of any habits like tobacco and alcohol usage and the duration of these habits were noted. The treatment modality rendered to the patient, whether surgery, radiation therapy, chemotherapy, a combination of any of these or palliative therapy was considered. The data was recorded registering the outcome of each treatment in terms of whether a tumor was persistent, recurred at the primary site, showed the presence of metastatic lymph nodes, distant metastasis or a second tumor. A residual tumor is based on the UICC TNM cancer staging system and refers to tumor cells remaining at the primary tumor site after attempts to remove cancer have been made. ${ }^{6}$ Tumours which reappeared after treatment and after a period during which a tumor could not be detected were referred to as recurrent tumors. ${ }^{7}$ A second malignancy that presents either simultaneously or after the diagnosis of a primary tumor has been termed second tumors. ${ }^{8}$

Tissue sections from formalin fixed paraffin embedded oral squamous cell carcinoma cases were stained with hematoxylin and eosin ( $\mathrm{H}$ and $\mathrm{E}$ ) to enable histopathological grading based on the new malignancy grading system of squamous cell carcinoma by Anneroth et al. ${ }^{9}$

Disease-free survival, overall survival, time of recurrence (if any), and mortality due to disease (if any) were chosen as prognosticators for the study. Disease-free survival was based on the time elapsed between the initial treatment of the tumor to the date of documentation of reappearance of the tumor of the same histological type. Overall survival (OS) was calculated from the time of diagnosis to the time of last follow-up or death from any cause and mortality due to disease or disease-specific survival (DSS) from the time of diagnosis to the time of last follow-up or death from oral squamous cell carcinoma. ${ }^{10}$

The various parameters were compared for statistical significance using the Chi-square test. Survival results were presented as overall patient survival for all causes of death, as well as disease-specific, related to death attributed to cancer. Survival curves were estimated by Kaplan-Meier method and comparisons were done using the log-rank test (Mantel-Cox). $P$ values that are equal to 0.05 or less were considered to be statistically significant. Statistical analysis was carried out using the SPSS software system (version 20).

\section{RESULTS}

\section{Patient Characteristics (Table 1)}

The age of the patients at the time of diagnosis ranged from 28 years to 81 years (mean $=57.9$ years). Seven out of 89 patients $(7.9 \%$ ) with primary OSCC were 40 years of age or younger. $56.2 \%$ of the patients were in their 50 's and 60 's. The cohort showed a male predominance of $69.7 \%$ $(n=62)$ with a male to female ratio of 2.2:1.

\section{Tobacco and Alcohol Use}

The cases showed the presence of various habits like smoking, smokeless tobacco or tobacco chewing, alcohol and the combination of smoking and alcohol. Of the patients, $13(15.9 \%)$ used neither tobacco nor alcohol. Most of the tobacco and alcohol users were in the age range of 51-70 years. Of the 7 patients below the age of 40 years, $57.1 \%(n=4)$ were not seen to be associated with any habits. Most of the females with OSCC had a habit of usage of smokeless tobacco $(74.1 \%, \mathrm{n}=20)$. Compared to the females, only 10 males reported usage of smokeless tobacco $(19.4 \%)$. However, more males reported usage of smoking and alcohol $(41.9 \%, \mathrm{n}=26)$. The data on the duration of the habits was available in only 36 cases which showed a mean of 27 years (median 25 years, range 7-52 years).

\section{Patient and Tumor Characteristics According to the Epithelial Origin of Carcinoma (Table 1)}

Most of the OSCCs originated from the non-keratinized epithelium $(42.7 \%, n=38)$, followed by keratinized epithelium, lateral tongue and the least arose from the dorsal surface of the tongue. The OSCCs originating from the dorsal surface of tongue were seen only in men. Majority of the cases originating from the non-keratinized mucosa and keratinized mucosa were associated with a history of smokeless tobacco usage ( $n=14$ and $n=12$ respectively) with five cases in each having no history of smoking or alcohol use. However, the dorsal surface of the tongue showed the least association with the habit $(n=1)$. Correlating the clinical stage of a tumor with the epithelial origin of carcinoma showed that $89 \%$ of the carcinomas $(n=34)$ originating from non-keratinized mucosa were diagnosed 
Table 1: Patient and tumor characteristics according to the epithelial origin of carcinoma

\begin{tabular}{|c|c|c|c|c|c|c|}
\hline & $\begin{array}{l}\text { Nonkeratinized } \\
\text { epithelium }\end{array}$ & $\begin{array}{l}\text { Keratinized } \\
\text { epithelium }\end{array}$ & $\begin{array}{l}\text { Lateral tongue } \\
\text { epithelium }\end{array}$ & Dorsal tongue & Total (\%) & $p$ value \\
\hline \multicolumn{7}{|l|}{ Age (in years) } \\
\hline 40 and below & 3 & 2 & 0 & 2 & 7 (7.9) & \multirow{6}{*}{$p=0.248$} \\
\hline $41-50$ & 9 & 9 & 1 & 2 & $21(23.6)$ & \\
\hline $51-60$ & 11 & 5 & 7 & 2 & $25(28.1)$ & \\
\hline $61-70$ & 10 & 11 & 1 & 3 & $25(28.1)$ & \\
\hline 71 and above & 5 & 4 & 2 & 0 & $11(28.1)$ & \\
\hline Total & 38 & 31 & 11 & 9 & $89(100)$ & \\
\hline \multicolumn{7}{|l|}{ Sex } \\
\hline Men & 28 & 17 & 8 & 9 & $62(69.7)$ & \multirow[t]{3}{*}{$p>0.05$} \\
\hline Women & 10 & 14 & 3 & 0 & 27 (30.3) & \\
\hline Total & 38 & 31 & 11 & 9 & $89(100)$ & \\
\hline \multicolumn{7}{|l|}{ Habit } \\
\hline None & 5 & 5 & 1 & 2 & $13(15.9)$ & \multirow{5}{*}{$p=0.358$} \\
\hline Smoking only & 7 & 3 & 2 & 1 & 13 (15.9) & \\
\hline $\begin{array}{l}\text { Smokeless } \\
\text { tobacco } \\
\text { (chewing) }\end{array}$ & 14 & 12 & 3 & 1 & $30(36.6)$ & \\
\hline Combined use & 9 & 8 & 4 & 5 & $26(31.7)$ & \\
\hline Total & 35 & 28 & 10 & 9 & $82(100)$ & \\
\hline \multicolumn{7}{|l|}{$\begin{array}{l}\text { Stage of } \\
\text { disease }\end{array}$} \\
\hline Stage 1 & 0 & 0 & 1 & 0 & $1 \quad(1.1)$ & \multirow{5}{*}{$p=0.029$} \\
\hline Stage 2 & 4 & 7 & 5 & 1 & 17 (19.1) & \\
\hline Stage 3 & 11 & 11 & 4 & 4 & $30(33.7)$ & \\
\hline Stage 4 & 23 & 13 & 1 & 4 & $41(46.1)$ & \\
\hline Total & 38 & 31 & 11 & 9 & $89(100)$ & \\
\hline \multicolumn{7}{|l|}{$\begin{array}{l}\text { Histological } \\
\text { classification }\end{array}$} \\
\hline Grade 1 & 4 & 1 & 3 & 2 & $10(11.2)$ & \multirow{4}{*}{$p=0.408$} \\
\hline Grade 2 & 30 & 27 & 7 & 6 & 70 (78.7) & \\
\hline Grade 3 & 4 & 3 & 1 & 1 & 9 (10.1) & \\
\hline Total & 38 & 31 & 11 & 9 & $89(100)$ & \\
\hline \multicolumn{7}{|l|}{$\begin{array}{l}\text { Lymph node } \\
\text { status }\end{array}$} \\
\hline \multicolumn{7}{|l|}{ Not involved } \\
\hline Involved by a & 13 & 11 & 5 & 5 & 34 (77.3) & \multirow{3}{*}{$p=0.87$} \\
\hline tumor & 4 & 4 & 1 & 1 & $10(22.7)$ & \\
\hline Total & 17 & 15 & 6 & 6 & $44(100)$ & \\
\hline \multicolumn{7}{|l|}{ Follow-up } \\
\hline No recurrence & 10 & 18 & 5 & 5 & $38(42.7)$ & \\
\hline Residual & 8 & 3 & 2 & 0 & 13 (14.6) & \\
\hline Recurrence & 15 & 7 & 2 & 2 & $26(29.2)$ & \\
\hline \multicolumn{7}{|l|}{$\begin{array}{l}\text { Clinically } \\
\text { diagnosed neck }\end{array}$} \\
\hline metastasis & 1 & 1 & 1 & 1 & $4(4.5)$ & \\
\hline $\begin{array}{l}\text { Metastasis } \\
\text { distant }\end{array}$ & 0 & 0 & 0 & 0 & $0(0)$ & \\
\hline Second tumor & 4 & 2 & 1 & 1 & $8(9.0)$ & \\
\hline Total & 38 & 31 & 11 & 9 & $89(100)$ & \\
\hline
\end{tabular}

at stages III and IV and this was clinically significant $(\mathrm{p}=$ 0.029). At least $77.4 \%(n=24)$ of carcinomas arising from keratinized mucosa were diagnosed at stages III and IV. Out of 11 cases originating from the lateral border of tongue, most were diagnosed at stage II $(\mathrm{n}=5)$ and stage III $(n=4)$. Only one case was present at stage IV. Among the cases originating from the dorsal tongue, only one case was diagnosed at stage II whereas the rest were diagnosed at stage III $(n=4)$ and stage IV $(n=4)$. Histopathologically, the majority of the OSCCs were moderately differentiated
$(78.7 \%, \mathrm{n}=70)$. One case each from lateral tongue $(9.09 \%$ $\mathrm{n}=1)$ and dorsal tongue $(11.1 \%, \mathrm{n}=1)$ was poorly differentiated, followed by non-keratinized epithelium $(10.5 \%$, $n=4)$ and keratinized epithelium $(9.7 \%, n=3)$.

\section{Lymph Node Status}

Neck dissection was performed in 44 of the 62 cases of OSCC treated with surgery. The lymph nodes of these cases were evaluated for the presence of involvement. Of these dissected lymph nodes, $22.7 \%$ (10/44) were 
involved by a tumor. Total of 10 cases (out of 44 ) showed lymph node metastasis of which four cases each were present in tumors arising from non-keratinized and keratinized epithelia and one case each was present in tumors originating from lateral and dorsal surfaces of the tongue.

\section{Treatment of Residual Disease/Recurrence/ Metastasis (Flow Chart 1)}

After the primary treatment, residual tumors were observed in 13 cases. One patient who was surgically treated initially received radiation therapy for a residual tumor. Rest of the twelve patients who were primarily treated by radiation therapy that comprised of external beam radiation, 60 Gy every alternate day, fractionated at 2 Gy for 5 days a week were then treated by surgery $(\mathrm{n}=8)$, chemotherapy $(\mathrm{n}=2)$ and palliative treatment $(\mathrm{n}=2)$ for a residual tumour.

Recurrence was seen in 26 patients, who were subsequently treated by surgery $(n=6)$, radiotherapy $(n=16)$ chemotherapy $(n=1)$ and 2 patients received palliative treatment. One patient did not continue further treatment.

Four patients were clinically diagnosed with neck metastasis (regional recurrences). Out of 4, two patients received radiation therapy, one was treated surgically, and one received palliative therapy.

A second tumor was seen in 8 patients who were treated with surgery (1), radiotherapy (4) and palliative (2). One patient did not report for treatment.

Flow Chart 1: Summary of treatment modalities and their outcome among 89 OSCC patient

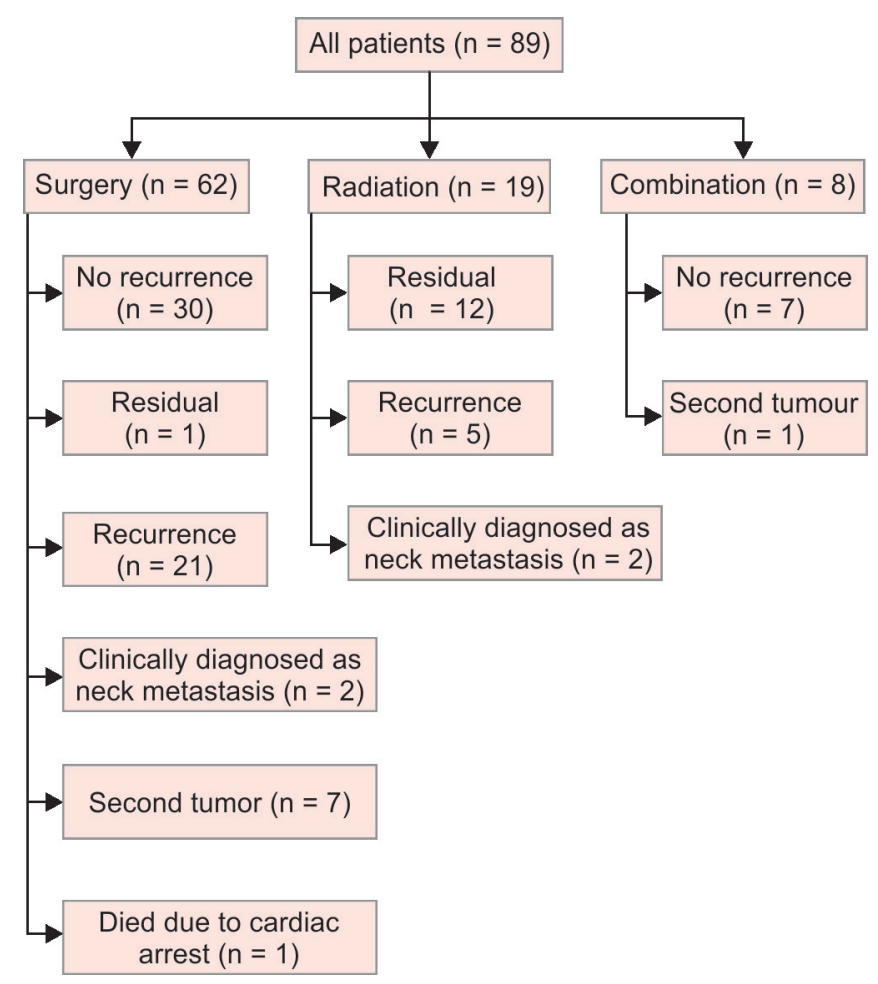

\section{Follow-up (Table 2)}

\section{Death}

All the patients were followed for a minimum period of 3 years (36 months). Sixteen patients died due to OSCC during the follow-up period, and two patients died due to other causes [cardiac arrest $(n=1)$ and sepsis $(n=1)]$. Amongst the patients who died of OSCC, 10 had OSCC arising from non-keratinized epithelium, 5 from keratinized epithelium and 1 from the lateral tongue. Among the patients who died due to OSCC, eight patients each were treated by surgery and radiation therapy. Most of the patients who died due to OSCC were in their sixth and seventh decade of life. The oldest patient was aged 74 (male) and was diagnosed at a clinical stage IV. The pathological grade of a tumor was moderately differentiated in 12 patients and poorly differentiated in 4 patients who died of OSCC.

\section{Recurrence}

A total of $29.2 \%$ of the cases $(n=26)$ showed recurrence. Recurrences were most commonly seen in patients with OSCC arising from non-keratinized mucosa $(n=15)$. Eleven of these patients received surgery as their primary mode of treatment, and four were treated with radiotherapy.

\section{Overall Survival Characteristics (Table 3 and Graph 1)}

On comparison with the type of epithelium from which the carcinoma arose, it was observed that carcinomas arising from the non-keratinized epithelium had the poorest outcome with a death rate of $27.7 \%(n=10)$ and disease-free survival of $38.8 \%(n=14)$. Thus the diseasefree survival was observed to be highest for keratinized epithelium $(64.5 \%, \mathrm{n}=20)$ and lowest for non-keratinized epithelium $(38.8 \%, \mathrm{n}=14)$. Statistically, these observations were, not significant ( $p>0.05, \mathrm{~ns})$.

On comparing the lymph node involvement with survival, we found that patients with lymph node involvement had lower three-year survival rate (70\%) as compared to those without involvement $(88.2 \%, \mathrm{n}=30)$. These observations were not statistically significant ( $p>0.05, \mathrm{~ns})$.

Correlation between the various treatment modalities and the survival showed that the combination of surgery and radiotherapy gave the best disease-free survival $(87.5 \%, n=7)$. On the contrary, radiotherapy was associated with the highest death rate of $44.4 \%(n=8)$, and a disease-free survival of only $22.2 \%(n=4)$. When surgery alone was used as a treatment modality, the disease-free survival was $55.7 \%(\mathrm{n}=34)$, and the death rate was $13.1 \%$ $(\mathrm{n}=8)$. This observation was statistically highly significant $(p<0.01)$. 
Table 2: Overall survival of 89 patients related to different parameters

\begin{tabular}{|c|c|c|c|c|}
\hline Parameter & $\begin{array}{l}\text { Dead due to } \\
\text { OSCC (16) }\end{array}$ & $\begin{array}{l}\text { Dead due to other } \\
\text { causes (2) }\end{array}$ & $\begin{array}{l}\text { Alive with } \\
\text { OSCC (26) }\end{array}$ & $\begin{array}{l}\text { Alive without } \\
\text { OSCC (45) }\end{array}$ \\
\hline \multicolumn{5}{|l|}{ Age } \\
\hline 40 and below & 1 & 0 & 1 & 5 \\
\hline $41-50$ & 2 & 0 & 11 & 8 \\
\hline $51-60$ & 6 & 0 & 6 & 13 \\
\hline $61-70$ & 4 & 0 & 7 & 14 \\
\hline 71 and above & 3 & 2 & 1 & 5 \\
\hline \multicolumn{5}{|l|}{ Gender } \\
\hline Male & 11 & 2 & 17 & 32 \\
\hline Female & 5 & 0 & 9 & 13 \\
\hline \multicolumn{5}{|l|}{ Habit } \\
\hline Smoking & 1 & 0 & 4 & 8 \\
\hline Smokeless tobacco (chewing) & 6 & 0 & 11 & 13 \\
\hline Combined & 5 & 1 & 9 & 11 \\
\hline No habits & 4 & 1 & 2 & 13 \\
\hline \multicolumn{5}{|l|}{ Site } \\
\hline Non-keratinized & 10 & 2 & 12 & 14 \\
\hline Keratinized & 5 & 0 & 6 & 20 \\
\hline Lateral tongue & 1 & 0 & 4 & 6 \\
\hline Dorsal tongue & 0 & 0 & 4 & 5 \\
\hline \multicolumn{5}{|l|}{ Clinical stage } \\
\hline Stage 1 & 0 & 0 & 0 & 1 \\
\hline Stage 2 & 2 & 0 & 3 & 12 \\
\hline Stage 3 & 5 & 0 & 7 & 18 \\
\hline Stage 4 & 9 & 2 & 16 & 14 \\
\hline \multicolumn{5}{|l|}{ Histopathological grade } \\
\hline Well-differentiated & 0 & 1 & 2 & 7 \\
\hline Moderately differentiated & 12 & 1 & 21 & 36 \\
\hline Poorly differentiated & 4 & 0 & 3 & 2 \\
\hline \multicolumn{5}{|l|}{ Lymph node involvement } \\
\hline Involved by a tumor & 3 & 0 & 4 & 3 \\
\hline Uninvolved & 4 & 0 & 9 & 21 \\
\hline \multicolumn{5}{|l|}{ Treatment } \\
\hline Surgery & 8 & 1 & 19 & 34 \\
\hline Radiotherapy & 8 & 0 & 6 & 4 \\
\hline Combined & 0 & 1 & 1 & 7 \\
\hline
\end{tabular}

Table 3: 3-year survival analysis (Log Rank test) for the study group

\begin{tabular}{lllll}
\hline Parameter & Variables & $N$ & Chi-square test & $p$ value \\
\hline Site & Non-keratinized & 38 & & 0.086 \\
& Keratinized & 31 & 6.576 & (Sig at 10\%) \\
& Lateral tongue & 11 & & \multirow{2}{*}{0.000 (vhs) } \\
& Dorsal tongue & 9 & & \\
\hline Treatment & Surgery & 62 & & 26.496 \\
& Radiotherapy & 19 & & \\
& Combination & 8 & & \\
\hline
\end{tabular}

The overall survival (OS) in this study group at the end of 3 years was $79.8 \%(n=71)$. The overall disease-free survival (DFS) was $50.6 \%(n=45)$. During the follow-up period, a total of $18 \%(\mathrm{n}=16)$ died due to disease (OSCC) and $2.2 \%(\mathrm{n}=2)$ died due to other causes.

\section{DISCUSSION}

Oral squamous cell carcinoma (OSCC) is considered to be a result of a multistep process which involves many aberrant genetic events. Tobacco usage and heavy consumption of alcohol are probably the best-known risk factors for the disease. Around $4-10 \%$ of the patients with OSCC are not exposed to these risk factors, and only a small proportion of tobacco-exposed individuals develop OSCC. ${ }^{11}$

The present study analyzed the patient and tumor characteristics of treated OSCC patients who had a follow-up of at least 36 months. An evaluation was made of any possible differences concerning the clinical and histopathological presentation of OSCC, the age and gender distribution of the patients and the outcome of the treatment compared with recently published data. Special attention was paid to the type of epithelium from which the tumors had originated. 


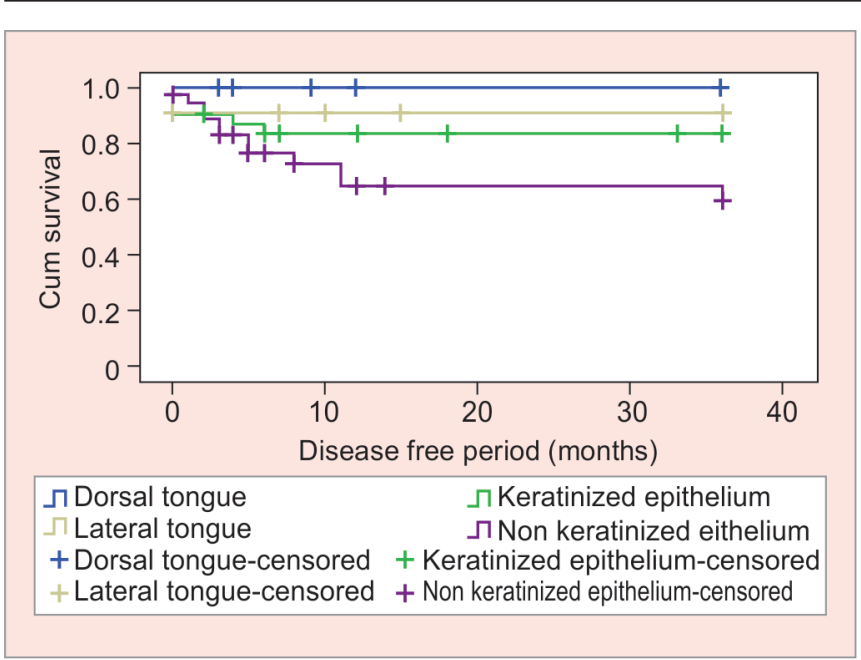

Graph 1: Kaplan-Meier survival plot showing the cumulative survival stratified as per the type of epithelium. X-axis shows the disease-free survival in months and $Y$-axis indicates the percentage of cumulative survival. Kaplan Meier survival analysis represents the percentage survival represented on a scale of $0-1$. The values 0.2 and 0.4 represent the percentages 20 and 40 , respectively.

\section{Age}

The mean age of the patients in the present study was 57.9 years (28-81 years). More than half the total number of patients in the present study were in their 50s and 60s, which is similar to the findings of a hospital-based study of 80 patients by Khandekar et al., ${ }^{12}$ and Shenoi et al..$^{13}$ wherein a majority of the patients belonged to the 51-60 year age group.

\section{Type of Epithelium}

Rautava et al. ${ }^{5}$ in his novel study on the prognostication of OSCC originating from different types of epithelia found that most of the squamous cell carcinomas originated from the keratinized mucosa, and none of the OSCCs (from a sample of 188 patients) originated from the specialized epithelium, i.e., from the dorsal surface of the tongue. However, in the present study, we found that the non-keratinized epithelium of the oral cavity (present in buccal mucosa and floor of mouth) was most commonly affected by OSCC, followed by the keratinized epithelium, the lateral surface of the tongue and finally the dorsal surface of tongue. Collins and Dawes have stated that the various types of oral mucosa differ in their relative extent in the oral cavity, with masticatory mucosa representing approximately $25 \%$, the specialized mucosa (dorsum of the tongue) approximately $15 \%$ and the lining mucosa approximately $60 \%$ of the total surface area of the oral lining. ${ }^{14,15}$ This may attribute to a higher incidence in the non-keratinized mucosa. Secondly, habits like chewing betel quid and areca with tobacco are highly prevalent in the Indian subcontinent. The carcinogenic agents such as benzopyrene and nitrosamine, from these, may be pooled in gravity-dependent areas such as buccal vestibule and floor of mouth which over a period may lead to a neoplastic change of the mucosa. ${ }^{16}$ Apart from this, the histology of the non-keratinized mucosa may account for the minor resistance to these agents. Epithelial tissues express different pairs of keratin proteins depending on epithelial cell type and stage of differentiation. Epidermal and gingival tissues express keratins K1 and K10 in the spinous layer while non-keratinizing tissue such as buccal mucosa and soft palate produce K4 and K13 in the suprabasal layers. ${ }^{17}$ The membrane coating granules of keratinized epithelium form a lipid-rich permeability barrier that limits the movement of carcinogenic agents through the intercellular spaces of the keratinized layer. The granules in the non-keratinized epithelium may also have a similar function. However, the barrier may not be as effective as in keratinized epithelia. The cells in the superficial part of the granular layer also develop a thickening made of protein involucrin on the inner aspect of their membrane that gives the keratinized layer considerable resistance to chemical solvents. ${ }^{4}$

Nine of eighty-nine cases originated from the dorsal surface of the tongue, and all of them were seen in males. The dorsal surface of the tongue was also least associated with the habit of smokeless tobacco. This could probably be explained by the fact that the dorsal surface of the tongue hardly comes in contact with the quid when it is placed in the vestibule. However, it may be directly exposed to the carcinogenic effects of tobacco smoking which is more prevalent in men.

The clinical staging of cancer is based on the TNM system, which had been labeled by many investigators as imperfect for prognostic purposes. However, the vast majority of authors accept that the disease staging has a crucial influence on the outcome. Carcinomas arising from non-keratinized epithelium showed a higher TNM stage (stages III and IV) indicative of a rapid increase in size as compared to the keratinized epithelium. This could be attributed to the innate multiplicative potential of the non-keratinized epithelium. It has a higher turn-over rate (approximately 23 days) as compared to the keratinized epithelium (about 53 days). ${ }^{4}$ Thus a minor trigger such as that of a carcinogenic stimulus will incite a faster rate of growth thereby accounting for the increased TNM stage. Another critical factor is that, though oral cancers occur at sites which are accessible for clinical examination and amenable to diagnosis by current diagnostic tools, the majority of the cases report late to the healthcare facility, most probably due to lack of awareness of the disease.

Rautava et al. ${ }^{5}$ also found that the prognosis was poor for the patients with OSCC originating from the keratinized epithelium with $58 \%$ mortality as more than 
$50 \%$ of these patients presented at stage IV of disease. The corresponding figures for the tumors arising from the non-keratinized and tongue epithelium were $43 \%$ and $39 \%$, respectively. In contrast to the above results, we found that the prognosis was poor for tumors originating from the non-keratinized epithelium with a mortality of $27.7 \%$ throughout three years. Also, the mortality associated with OSCCs arising from keratinized epithelium and lateral tongue epithelium was $16.1 \%$ and $9 \%$, respectively. This could probably be attributed to the fact that in our study most of the OSCCs originating from the non-keratinized epithelium were diagnosed at an advanced stage of disease as compared to those from other epithelia.

\section{Lymph Node Involvement}

The prognostic value of lymph node involvement in patients with OSCC has been assessed in various studies. Tankéré et al. ${ }^{18}$ concluded from their study of 137 OSCC patients that the histologic status of lymph node correlated well with the survival rate as patients without lymph node invasion had a 5-year survival rate that was almost three times as high as those with lymph node invasion (42.8\% vs $17.5 \%)$. Shingaki et al. ${ }^{19}$ in an analysis of 77 patients with oral tongue carcinomas, found that the five-year survival for the node-positive group was $46 \%$ which was significantly lower than the $86 \%$ for the node-negative group.

In agreement with the reports of Tankéré et al. and Shingaki et al. it was seen in the present study that the overall three-year survival for patients with lymph node involvement was lower (70\%) than those without lymph node involvement (88.2\%).

\section{Treatment}

Our findings regarding the outcome of therapy are in concordance with those of Jesse and Fletcher, ${ }^{20}$ and Bartelink et al. ${ }^{21}$ who showed that the possibility of survival was significantly associated with the modality of treatment with better results achieved with a combination of surgery and postoperative radiotherapy as opposed to surgery alone, and especially with radiotherapy alone. By contrast, Ilstad et al. ${ }^{22}$ in a study of 542 patients with squamous cell carcinoma of the head and neck found that the type of therapy used did not significantly influence survival after adjusting for stage. Combined therapy in their series, however, consisted of preoperative irradiation followed by surgery.

\section{Recurrence}

In the present study, a total of $29.2 \%$ of the patients developed recurrences at the site of a primary tumor after the initial mode of treatment. Braakhuis et al..$^{23}$ suggested the growth of the incompletely resected carcinoma as a possible cause of recurrence in some cases. The origin of a tumor at a particular site would indicate the presence of genetically conditioned oral mucosa (field cancerization effect). The presence of a field with genetically altered cells remains a continuous risk factor for recurrent neoplasm.

Chen et al. ${ }^{24}$ in their study on patients who underwent resection of their primary tumors with satisfactory surgical margins found $12 \%$ incidence of recurrence at the primary site. Recurrence rates were found to be higher for stages T3 and T4 than for the earlier stages.

Rautava et al. ${ }^{5}$ found that the recurrences were most commonly seen in carcinomas arising from the tongue epithelium. Contrary to their finding, the present study found most of the recurrences in carcinomas arising from the non-keratinized mucosa.

\section{Survival Analysis}

Rautava et al..$^{5}$ in their study of 188 patients of OSCC reported a 5 -year overall survival of $38 \%$ and diseasespecific survival of $58 \%$. In a study of 115 patients done in Southern India by Iype et al. ${ }^{25}$ in young adults with SCC of the tongue, the overall survival at 3 years was $91 \%$ and the disease-free survival at 3 years was $63 \%$. In our study of 89 patients of OSCC, we found an overall survival of $79.8 \%$ and disease-free survival of $50.6 \%$. In our study from among the different sites, survival analysis showed that OSCCs arising from non-keratinized epithelium were associated with poorer prognosis and this value was deemed significant at $10 \%$ interval of the $p$-value. The poorer prognosis may be explained by the fact that non-keratinized lining epithelium may be less protective and more vulnerable to the effect of carcinogens.

Thus studies with larger sample size and longer follow-up than in the present study may further help to establish a strong relationship between OSCCs originating from different epithelial and their prognosis. This could have a bearing on the treatment modality that the surgeon would use to best manage such lesions.

\section{CONCLUSION}

The present study, while limited in its sample size and follow-up, concluded that the originating epithelium has a bearing on the prognosis of OSCCs as different types of epithelia may have different molecular characteristics that could influence their vulnerability to carcinogens. This phenotypic variation, which needs to be further researched, may be the reason for the differing clinical behavior of OSCC and its response to different treatment modalities. 


\section{REFERENCES}

1. Howell RE, Wright BA, Dewar R. Trends in the incidence of oral cancer in Nova Scotia from 1983 to 1997. Oral Surg Oral Med Oral Pathol Oral Radiol Endod. 2003;95(2):205-212.

2. Del Corso G, Villa A, Tarsitano A, Gohel A. Current trends in oral cancer: A review. Cancer Cell and Microenvironment 2016;3:e1332.

3. Maringá V. Acta Scientiarum. Health Sciences 2014;36(2): 273-279

4. Nanci A. Ten Cate's Oral Histology Development, Structure 7th and Function. Edition Mosby Inc. Noida. India 2008. P. 323-333.

5. Rautava J, Luukkaa M, Heikinheimo K, Alin J, Grenman R, Happonen RP. Squamous cell carcinomas arising from different types of oral epithelia differ in their tumour and patient characteristics and survival. Oral Oncol. 2007; 43: 911-919.

6. Wittekind C, Compton CC, Greene FL, Sobin LH. TNM residual tumor classification revisited. Cancer 2002; 94(9): 2511-6

7. Dorland's Illustrated Medical Dictionary $28^{\text {th }}$ edition W.B. Saunders Page 1434

8. BaxiSS, Pinheiro LC, Patil SM, Pfister DG, Oeffinger KC, Elkin EB. Causes of death in long-term survivors of head and neck cancer. Cancer. 2014 May 15;120(10):1507-1513.

9. Anneroth G, Batsakis J, Luna M. Review of the literature and a recommended system of malignancy grading in oral squamous cell carcinomas. Scand J Dent Res. 1987;95(3):229-49.

10. Al-Rajhi N, Khafaga Y, El-Husseiny J, Saleem M, Mourad W, Al-Otieschan A, Al-Amro A. Early stage carcinoma of oral tongue: prognostic factors for local control and survival. Oral oncology. 2000;36(6):508-514.

11. Oliveira LR, Ribeiro-Silva A, Costa JP, Simões AL, Di Matteo MA, Zucoloto S. Prognostic factors and survival analysis in a sample of oral squamous cell carcinoma patients. Oral Surgery, Oral Medicine, Oral Pathology, Oral Radiology, and Endodontology. 2008;106(5):685-695.

12. Khandekar SP, Bagdey PS, Tiwari RR. Oral Cancer and Some Epidemiological Factors: A Hospital Based Study. Indian Journal of Community Medicine 2006;31(3):157-159

13. Shenoi R, Devrukhkar V, Chaudhuri, Sharma B K, Sapre S B, Chikhale A. Demographic and clinical profile of oral squamous cell carcinoma patients: A retrospective study. Indian J Cancer 2012;49:21-26
14. Collins LM, Dawes C. The surface area of the adult human mouth and thickness of the salivary film covering the teeth and oral mucosa. Journal of dental research. 1987;66(8):13001302.

15. Squier CA. The permeability of oral mucosa. Crit Rev Oral Biol Med. 1991;2(1):13-32

16. Schmidt BL, Dierks EJ, Homer L, Potter B. Tobacco smoking history and presentation of oral squamous cell carcinoma. J Oral Maxillofac Surg. 2004;62(9):1055-1058

17. Presland RB, Jurevic RJ. Making sense of the epithelial barrier: what molecular biology and genetics tell us about the functions of oral mucosal and epidermal tissues. J Dent Educ. 2002;66(4):564-574.

18. Tankéré F, Camproux A, Barry B, Guedon C, Depondt J, Gehanno P. Prognostic value of lymph node involvement in oral cancers: a study of 137 cases. Laryngoscope. 2000;110(12): 2061-2065.

19. Shingaki S, Takada M, Sasai K, Bibi R, Kobayashi T, Nomura $\mathrm{T}$, Saito C. Impact of lymph node metastasis on the pattern of failure and survival in oral carcinomas. The Am J S. 2003;185(3):278-284.

20. Jesse RH, Fletcher GH. Treatment of the neck in patients with squamous cell carcinoma of the head and neck. Cancer. 1977;39:868-872

21. Bartelink H, Breur K, Hart G, Annyas B, van Slooten E, Snow $\mathrm{G}$. The value of postoperative radiotherapy as an adjuvant to radical neck dissection. Cancer.1983;52(6):1008-1013.

22. Ildstad ST, Tollerud DJ, Bigelow ME, Remensnyder JP. A multivariate analysis of determinants of survival for patients with squamous cell carcinoma of the head and neck. Ann Surg. 1989;209(2):237-241.

23. Braakhuis BJ, Tabor MP, Kummer JA, Leemans CR, Brakenhoff RH. A genetic explanation of Slaughter's concept of field cancerization: evidence and clinical implications. Cancer Res. 2003;63(8):1727-1730

24. Chen TY, Emrich LJ, Driscoll DL. The clinical significance of pathological findings in surgically resected margins of the primary tumor in head and neck carcinoma. Int J Radiat Oncol Biol Phys. 1987;13(6):833-837

25. Mathew Iype E, Pandey M, Mathew A, Thomas G, Sebastian P, Krishnan Nair M. Squamous cell carcinoma of the tongue among young Indian adults. Neoplasia. 2001;3(4): 273-277. 